\title{
Structural Characterization of Soluble Lignin in the Pre- Hydrolysis Liquor of Bamboo-willow Dissolving Pulp
}

\author{
Jinchao Zhang, ${ }^{\mathrm{a}}$ Chaojun $\mathrm{Wu},{ }^{\mathrm{a}, \mathrm{b}}, *$ Dongmei $\mathrm{Yu},{ }^{\mathrm{a}}$ and Yachong $\mathrm{Zhu}{ }^{\mathrm{a}}$ \\ The soluble lignin present in the pre-hydrolysis liquor $(\mathrm{PHL})$ is detrimental \\ for value-added utilization of the $\mathrm{PHL}$ from production of kraft-based \\ dissolving pulp. In this paper, the soluble lignin was separated from PHL \\ by activated carbon adsorption and subsequent desorption with methanol. \\ The structural characteristics of the soluble and dioxane lignins (from \\ bamboo-willow material) were analyzed by Fourier transform infrared \\ (FTIR) spectroscopy, nuclear magnetic resonance (NMR), and \\ thermogravimetric analysis (TGA). The FTIR and proton-NMR results \\ showed that cleavage of $\beta-O-4$ aryl-ether linkages and demethylation \\ occurred in the lignin structure during the pre-hydrolysis. The main \\ linkages between structural monomeric units of the soluble lignin were $\beta$ - \\ $\beta, \beta-5, \beta-1$, and $\beta-O-4$. Additionally, the TGA results showed that the \\ residual char yield at $800{ }^{\circ} \mathrm{C}$ of the soluble and dioxane lignins were $33.4 \%$ \\ and $35.3 \%$, respectively. Therefore, the soluble lignin obtained from PHL \\ possessed thermal stability comparable to that of dioxane lignin, and can \\ be used as a renewable source for carbon fiber.
}

Keywords: Dissolving pulp; Pre-hydrolysis liquor; Soluble lignin; Structural characteristics

Contact information: a: State Key Laboratory of Biobased Material and Green Papermaking, Qilu University of Technology, Shandong Academy of Sciences, Jinan, 250353; b: State Key Laboratory of Pulp and Paper Engineering, South China University of Technology, Guangzhou, 510640;

*Corresponding author: chaojunwu2007@163.com

\section{INTRODUCTION}

Pre-hydrolysis liquor (PHL) is considered a waste liquor produced in the first step of the kraft-based dissolving pulp production process. The PHL contains a substantial amount of degradation products derived from lignocellulosic materials, such as saccharides formed from hemicelluloses, lignin derivatives, and acetic acid. The saccharides present in the PHL can be further processed to produce biofuels, biochemicals, functional oligosaccharides, etc. (Kumar and Christopher 2017). The lignin present in the PHL can be used to produce biofuel, plastics, phenols, etc. (Schorr et al. 2014). However, the presence of lignin in the PHL is detrimental for value-added utilization of saccharides. Lignin adversely affects the fermentation of xylose/xylan in the PHL into ethanol or xylitol (Lee et al. 2013). In addition, the presence of lignin in the PHL may hinder the separation and concentration of acetic acid (Yang et al. 2013a). Therefore, the removal of soluble lignin from the PHL is essential for the further resource utilization of the PHL. Such as approach not only conforms to the forest biorefinery concept, but also can add additional revenue to the dissolving pulp industry.

In the pre-hydrolysis stage, the lignin macromolecules are depolymerized and degraded under high temperature and acidic reaction conditions. During this step, the main $\beta$-O-4 aryl ether linkages in lignin undergo homolytic cleavage, resulting in an increase in the content of free phenolic hydroxyl groups (Evtuguin et al. 2001). 
After depolymerization, the lignin is converted into oligomers, dimers, and monomers rich in phenolic hydroxyl groups (Bardet et al. 1985). As the pre-hydrolysis step proceeds, the lignin moieties further undergo repolymerization or condensation reactions as shown by the increase in the contents of -C-C- bonds and the decrease of $\beta$-O-4 linkages (Capanema et al. 2005). Chua and Wayman (1979) studied the hot water pre-hydrolysis of poplar wood and observed the formation of lignin condensation products, which was attributed to a series of reactions occurring between lignin aromatic rings, furfural, and hydroxymethyl-furfural. Under strong acidic conditions, the diphenylmethane structure is the main product of the lignin condensation reaction. During the pre-hydrolysis, a stilbene structure also can be formed from the $\beta$ - 1 structure and the cleavage of $\beta$-O-4 bonds (Leschinsky et al. 2008). Mašura (1987) showed that lignin would be re-deposited in the later stage of pre-hydrolysis, causing re-adsorption to the surface of wood chips. The condensation and re-deposition of lignin during the pre-hydrolysis process will impart adverse effects on subsequent cooking and bleaching.

The structural characteristics of soluble lignin in the PHL have a great influence on its specific removal. Therefore, it is important to study the structure and properties of soluble lignin in the PHL for the selective removal of soluble lignin. Various investigations have been conducted on separation and structural characterization of lignin in the PHL. Yang et al. (2013b) separated lignin from the PHL via acidification, and characterized its structure. Results showed that PHL lignin has a lower methoxyl content and molecular weight compared to dioxane lignins. Chen et al. (2019) studied the structure of lignin after separating lignin from PHL by hydrothermal acid hydrolysis, the results showed that the lignin samples obtained revealed relatively high molecular weight, surface hydrophilicity, and thermal stability. Tong et al. (2017) studied the structure of lignin in the PHL via acidification treatment (AT) and rotary vacuum evaporation treatment (RVET), and the results showed that the RVET lignin could be identified as $p$-hydroxyphenyl $(\mathrm{H})$, syringyl $(\mathrm{S})$, guaiacyl $(\mathrm{G})$ lignins, and the AT lignin was mainly composed of S-lignin that had $\beta$ $1, \beta-5, \beta-\mathrm{O}-4$, and $\beta-\beta$ bonds. Wang et al. (2014a) separated lignin samples from the PHL by activated carbon adsorption, and studied the effect of laccase treatment on the molecular weight of lignin in the PHL.

However, the structure of soluble lignin in PHL has not been clearly studied. To enhance the removal of soluble lignin from PHL, the structural characteristic of soluble lignin should be further explored. The study of Wang et al. (2014b) demonstrated that phenolic hydroxyl groups $(\mathrm{PhOH})$ in lignin played an important role in the removal lignin from PHL.

In the present study, the PHL of bamboo-willow dissolving pulp was prepared by using the optimized parameters in our previous research (Zhang et al. 2019). The soluble lignin was separated from PHL via activated carbon adsorption and subsequent desorption using methanol, and then the soluble lignin samples thus obtained were purified. For comparison, the dioxane lignin was also prepared and separated from the bamboo-willow material. The isolated lignin samples were characterized by Fourier transform infrared (FTIR), proton nuclear magnetic resonance $\left({ }^{1} \mathrm{H}-\mathrm{NMR}\right)$, two dimensional heteronuclear single quantum correlation (2D-HSQC) spectroscopies, and thermogravimetric analysis (TGA). 


\section{EXPERIMENTAL}

\section{Materials}

The raw material of bamboo-willow (Salix sp or zhuliu in Chinese) was provided by one of the forestry centers in the Xinjiang autonomous region of Wulumuqi, China. The chemical compositional analysis of the raw material revealed $77.2 \%$ holocellulose, $40.4 \%$ $\alpha$-cellulose, $24.1 \%$ pentosan, $20.3 \%$ acid-insoluble lignin, and $3.46 \%$ acid-soluble lignin (Zhang et al. 2019). Chipped bamboo-willow was screened to obtain particles with the dimensions of $15 \mathrm{~mm}$ to $20 \mathrm{~mm}$ (length) $\times 10 \mathrm{~mm}$ to $20 \mathrm{~mm}$ (width) $\times 3 \mathrm{~mm}$ to $5 \mathrm{~mm}$ (thickness). A portion of the wood chips was taken for moisture content determination for subsequent experiments.

\section{Methods}

Preparation of PHL

Pre-hydrolysis was performed in an electrically heated stainless-steel digester (15L) with $1.0 \mathrm{~kg}$ oven-dried chips at a reaction temperature of $160{ }^{\circ} \mathrm{C}$ for $90 \mathrm{~min}$ (Zhang et al. 2019). Deionized water was added to reach a 6:1 liquid-to-wood ratio. The dosage of phosphoric acid used was $0.5 \%$ (based on the oven-dried weight of the materials). Upon completion of pre-hydrolysis, the digester was cooled by decompressing the exhaust valve, which subsequently separated the PHL from the solid mass. The collected PHL was slowly filtered using two-tiers of quantitative filter papers and then refrigerated for experimental use. The contents of soluble lignin, arabinose, galactose, glucose, xylose, mannose, and total sugars in original PHL were 4.84, 0.91, 1.00, 4.02, 8.67, 1.17, and $15.8 \mathrm{~g} / \mathrm{L}$, respectively.

\section{Analytical methods}

The soluble lignin content in the PHL was measured via ultraviolet visible (UVvis) spectroscopy (Agilent 8453; Agilent Technologies Inc., Palo Alto, CA, USA) at a wavelength of $205 \mathrm{~nm}$, according to TAPPI um 250 (2000) (Wang et al. 2014a).

The sugars content in the PHL was measured using an indirect method based on quantitative acid hydrolysis of the liquid sample. To convert the oligomeric sugars in the PHL to monomeric sugars, the PHL was acid hydrolyzed using $4 \mathrm{wt} \%$ sulfuric acid at 121 ${ }^{\circ} \mathrm{C}$ for $1 \mathrm{~h}$ in an oil bath according to a technical report from the National Renewable Energy Laboratory (NREL) (Sluiter et al. 2006; Shen et al. 2011). The acid-hydrolyzed PHL was then diluted, and the content of monomeric sugars was measured. The monomeric sugars were measured using high-performance anion-exchange chromatography coupled with a pulsed amperometric detector (HPAEC-PAD) and an HPAEC-PAD system (ICS5000; Thermo Fisher Scientific, Sunnyvale, CA, USA) equipped with a CarboPac PA20 analytical column $(3 \mathrm{~mm} \times 150 \mathrm{~mm})$ (Thermo Fisher Scientific, Sunnyvale, CA, USA) and guard column $(3 \mathrm{~mm} \times 30 \mathrm{~mm})$. The samples were filtered through $0.22-\mu \mathrm{m}$ syringe filters prior to injection. The concentration of the sugars after this additional hydrolysis stage reflected the total sugars content of the PHL (Shen et al. 2011).

\section{Lignin isolation from PHL}

The method of separating lignin from the PHL was achieved by following the method of Shen et al. (2013) and Wang et al. (2014a). The mixture of PHL and activated carbon at a ratio of $30: 1(\mathrm{~m} / \mathrm{m})$ was shaken at $250 \mathrm{rpm}$ at room temperature for $5 \mathrm{~h}$. Then, the mixture was filtered with Whatman (Q8) filter paper and air-dried at room temperature 
for $48 \mathrm{~h}$. The air-dried lignin/activated carbon mixture was then mixed with methanol at a ratio of 30:1 at room temperature for $5 \mathrm{~h}$ at $250 \mathrm{rpm}$ for three replicates. Finally, the lignin sample was obtained by filtration followed by vacuum rotary evaporation (IKA, Staufen, Germany), and dried in a vacuum oven with $\mathrm{P}_{2} \mathrm{O}_{5}$ at $50{ }^{\circ} \mathrm{C}$.

\section{Lignin isolation from raw material}

The wood meal of 40/60-mesh was extracted with benzene-ethanol for $8 \mathrm{~h}$, and vacuum-dried over $\mathrm{P}_{2} \mathrm{O}_{5}$. The extracted wood meals were extracted with an acidic aqueous dioxane $(90 \% \mathrm{v} / \mathrm{v})$ solution for $1 \mathrm{~h}$, in $\mathrm{N}_{2}$ atmosphere. The $\mathrm{HCl}$ concentration in the dioxane solution was $0.2 \mathrm{~mol} / \mathrm{L}$. The dioxane solution-to-wood meal ratio was kept at 8:1. Upon completion of refluxing, the mixture was filtered with a Buchner funnel, and the residue was washed with an aqueous dioxane solution $(90 \% \mathrm{v} / \mathrm{v})$. The filtrate was neutralized with solid $\mathrm{Na}_{2} \mathrm{CO}_{3}$, and then the filtrate was collected by filtration. The filtrate was concentrated in a rotary vacuum evaporator at $40{ }^{\circ} \mathrm{C}$, and the concentrated filtrate was slowly dropped into deionized water to precipitate lignin, the lignin precipitate was washed, and vacuumdried with $\mathrm{P}_{2} \mathrm{O}_{5}$.

\section{Lignin purification}

Lignin purification was achieved by following the method of Yang et al. (2013b). The crude lignin separated from PHL and raw material were dissolved in dioxane solution $(90 \% \mathrm{v} / \mathrm{v})$, and precipitated in ether by magnetic stirrer. The precipitated lignin was vacuum-dried with $\mathrm{P}_{2} \mathrm{O}_{5}$.

\section{Analysis Methods}

FTIR analysis

The FTIR spectra of the samples were recorded with an IR-Prestige-21 spectrometer (Shimadzu, Kyoto, Japan). The dried lignin samples were embedded in $\mathrm{KBr}$ pellets at concentrations of approximately $1 \mathrm{mg} / 100 \mathrm{mg} \mathrm{KBr}$. The spectra was recorded in the absorption mode in the $4000 \mathrm{~cm}^{-1}$ to $400 \mathrm{~cm}^{-1}$ range.

\section{${ }^{1} H$-NMR analysis}

The ${ }^{1} \mathrm{H}-\mathrm{NMR}$ spectra of the samples were recorded on an AVANCE II $400 \mathrm{MHz}$ NMR spectrometer (Bruker, Karlsruhe, Germany). Samples of approximately $30 \mathrm{mg}$ were completely dissolved in $0.6 \mathrm{~mL}$ of dimethyl sulphoxide (DMSO-d6, 99.99\%; Cambridge Isotope Laboratories, Andover, MA, USA). The chemical shifts were calibrated relative to the signals of DMSO solvent, which was used as an internal standard at $2.49 \mathrm{ppm}$ for the ${ }^{1} \mathrm{H}-\mathrm{NMR}$ spectra. The acquiring time (AQ) was $3.98 \mathrm{~s}$, and the relaxation time used was $1.0 \mathrm{~s}$.

\section{D-HSQC analysis}

The 2D-HSQC analysis of the samples were recorded on an AVANCE II $400 \mathrm{MHz}$ NMR spectrometer (Bruker, Karlsruhe, Germany). Samples of approximately $40 \mathrm{mg}$ was dissolved in $0.6 \mathrm{~mL}$ of DMSO-d6 was used for NMR measurement.

$T G A$

The thermal stability of the samples was measured using a Q50 thermogravimetric analyzer (TA Instruments, New Castle DE, USA). Approximately $3.0 \mathrm{mg}$ of sample was 
heated from room temperature to $800{ }^{\circ} \mathrm{C}$ at a heating rate of $10{ }^{\circ} \mathrm{C} / \mathrm{min}$ under $\mathrm{N}_{2}$ atmosphere.

\section{RESULTS AND DISCUSSION}

\section{FTIR Spectroscopy}

The FTIR spectra of both the soluble and dioxane lignins were recorded, and are shown in Fig. 1. The peak assignments are presented in Table 1 following previous studies (Jahan and Mun 2007; Zhao et al. 2014; Constant et al. 2015). The absorption peaks at $1515 \mathrm{~cm}^{-1}$ and $1605 \mathrm{~cm}^{-1}$ were assigned to the skeletal vibrations of the benzene ring (aromatic units) and were selected as qualitative absorption of lignin (Buta et al. 1989; Kang et al. 2012). The absorption peaks at approximately $3410 \mathrm{~cm}^{-1}$ and $3460 \mathrm{~cm}^{-1}$ were assigned to the stretching of $\mathrm{O}-\mathrm{H}$ groups, inclusive of alcoholic and phenolic hydroxyl groups (Yang et al. 2013b).

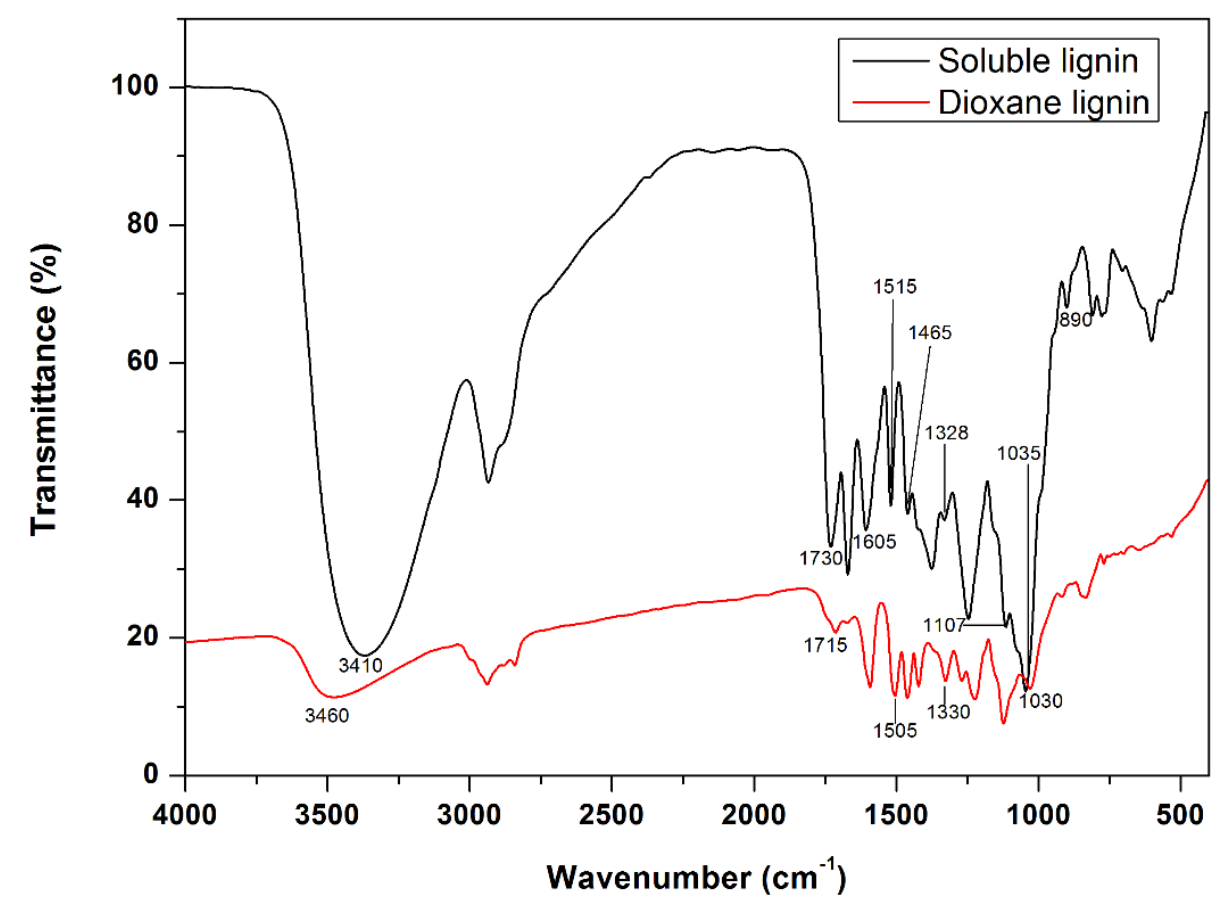

Fig. 1. FTIR spectra of soluble and dioxane lignins

The absorbance peak at $890 \mathrm{~cm}^{-1}$ was assigned to isolated aromatic $\mathrm{C}-\mathrm{H}$ bond vibrations (Lora and Wayman 1980), which indicated that there was a condensation structure in the soluble lignin obtained from PHL. The band at $1505 \mathrm{~cm}^{-1}$ was shifted to $1515 \mathrm{~cm}^{-1}$ in soluble lignin fraction, which was probably caused by the decreased amount of $\beta$-O-4 linkages (Yang et al. 2013b). The band at $1325 \mathrm{~cm}^{-1}$ to $1330 \mathrm{~cm}^{-1}$ was related to the syringyl (S-type) structural unit of lignin, and the band at $1030 \mathrm{~cm}^{-1}$ to $1035 \mathrm{~cm}^{-1}$ belongs to the $\mathrm{C}-\mathrm{H}$ bending of guaiacyl (G-type) structural units. These results indicated that there were mainly syringyl (S-type) and guaiacyl (G-type) structural units in both soluble $\left(1328 \mathrm{~cm}^{-1}\right.$ and $\left.1035 \mathrm{~cm}^{-1}\right)$ and dioxane $\left(1330 \mathrm{~cm}^{-1}\right.$ and $\left.1030 \mathrm{~cm}^{-1}\right)$ lignin fractions. $\mathrm{A} \mathrm{C}=\mathrm{O}$ structure in an unconjugated ketone group ( $\beta$-carbonyl group) was observed at 1730 
$\mathrm{cm}^{-1}$ (soluble lignin) and $1715 \mathrm{~cm}^{-1}$ (dioxane lignin). In addition, the band at $1465 \mathrm{~cm}^{-1}$ indicated $\mathrm{C}-\mathrm{H}$ deformation and aromatic vibration. Further, the infrared spectra of the obtained soluble lignin showed that there was a weak absorbance peak at $1107 \mathrm{~cm}^{-1}$. The band at $1107 \mathrm{~cm}^{-1}$ denoted the $\mathrm{C}-\mathrm{O}$ vibration in carbohydrates (Tong et al. 2017), indicating that the soluble lignin obtained by activated carbon adsorption from PHL contained carbohydrates component.

Table 1. Assignments of FTIR Spectra of Soluble and Dioxane Lignins

\begin{tabular}{|c|c|c|c|}
\hline $\begin{array}{l}\text { Wavenumber } \\
\left(\mathrm{cm}^{-1}\right)\end{array}$ & Assignments & $\begin{array}{l}\text { Soluble } \\
\text { Lignin }\end{array}$ & $\begin{array}{l}\text { Dioxane } \\
\text { Lignin }\end{array}$ \\
\hline 3400 to 3460 & $\mathrm{O}-\mathrm{H}$ Stretching & 3410 & 3460 \\
\hline 2842 to 3000 & $\mathrm{C}-\mathrm{H}$ Stretch in methyl and methylene groups & $\begin{array}{l}2940 \\
2880\end{array}$ & 2940 \\
\hline 1709 to 1738 & $\begin{array}{c}\mathrm{C}=\mathrm{O} \text { Stretch in unconjugated ketone, carbonyl, } \\
\text { and ester groups }\end{array}$ & 1730 & 1715 \\
\hline 1655 to 1675 & $\begin{array}{c}\mathrm{C}=\mathrm{O} \text { Stretching in conjugated } p \text {-substituted aryl } \\
\text { ketones }\end{array}$ & 1670 & 1675 \\
\hline 1593 to 1605 & $\begin{array}{l}\text { Aromatic skeleton vibrations plus } \mathrm{C}=\mathrm{O} \\
\text { stretching; } \mathrm{S}>\mathrm{G}: \mathrm{G}_{\text {condensed }}>\mathrm{G}_{\text {etherified }}\end{array}$ & 1605 & 1594 \\
\hline 1505 to 1515 & Aromatic skeleton vibrations ( $\mathrm{G}>\mathrm{S}$ ) & 1515 & 1505 \\
\hline 1460 to 1470 & $\begin{array}{c}\text { C-H Deformations (asymmetrical in }-\mathrm{CH}_{3} \text { and } \\
-\mathrm{CH}_{2^{-}} \text {) }\end{array}$ & 1465 & 1462 \\
\hline 1422 to 1430 & $\begin{array}{l}\text { Aromatic skeletal vibrations combined with } \mathrm{C}-\mathrm{H} \\
\text { in plane deformations }\end{array}$ & 1425 & 1422 \\
\hline 1365 to 1370 & $\begin{array}{c}\text { Aliphatic } \mathrm{C}-\mathrm{H} \text { stretching in }-\mathrm{CH}_{3} \text { and phenolic } \\
-\mathrm{OH} \text { groups }\end{array}$ & 1370 & 1370 \\
\hline 1325 to 1330 & $\begin{array}{c}\text { Condensed } S \text { and } G \text { rings ( } G \text { ring bound via } \\
\text { position } 5 \text { ), syringyl unit }\end{array}$ & 1328 & 1330 \\
\hline 1266 to 1270 & G Ring plus $C+O$ stretching, guaiacyl unit & - & 1270 \\
\hline 1245 & - & 1245 & - \\
\hline 1221 to 1230 & $\begin{array}{c}\mathrm{C}-\mathrm{C}+\mathrm{C}-\mathrm{O}+\mathrm{C}=\mathrm{O} \text { Stretchings (G } \text { Gondensed }_{\text {Getherified }} \text { ) } \\
\text { ( }\end{array}$ & - & 1221 \\
\hline 1166 & $\begin{array}{c}\text { Typical for HGS lignins; } \mathrm{C}=\mathrm{O} \text { in ester groups } \\
\text { (conjugated) }\end{array}$ & 1166 & 1166 \\
\hline 1140 & $\begin{array}{c}\text { Aromatic } \mathrm{C}-\mathrm{H} \text { in plane deformation } \\
\text { (typical of G unit; } \mathrm{G}_{\text {condensed }}>\text { Getherified) }\end{array}$ & - & - \\
\hline 1125 to 1128 & $\begin{array}{l}\text { Typical of S unit; also secondary alcohol and } \\
\qquad=\mathrm{O} \text { stretching }\end{array}$ & - & - \\
\hline 1107 & C-O Vibration in carbohydrate & 1107 & - \\
\hline 1085 & $\begin{array}{c}\text { C-O Deformation in secondary. alcohol and } \\
\text { aliphatic ether }\end{array}$ & - & - \\
\hline 1030 to 1035 & $\begin{array}{c}\text { Aromatic } \mathrm{C}-\mathrm{H} \text { in plane deformation }(\mathrm{G}>\mathrm{S}) \text { plus } \\
\mathrm{C}-\mathrm{O} \text { deformation in primary alcohols plus } \mathrm{C}-\mathrm{H} \\
\text { stretching (unconjugated) }\end{array}$ & 1035 & 1030 \\
\hline 966 to 990 & $-\mathrm{C}=\mathrm{C}-$ Out of plane deformation (trans) & - & - \\
\hline 915 to 925 & $\mathrm{C}-\mathrm{H}$ Out of plane (aromatic ring) & - & 920 \\
\hline 853 to 858 & $\begin{array}{c}\text { C-H Out of plane in positions 2, 5, and } 6 \text { (G- } \\
\text { units) }\end{array}$ & - & - \\
\hline 834 to 835 & $\mathrm{C}-\mathrm{H}$ Out of plane in positions 2 and 6 of S-units & - & - \\
\hline 817 to 832 & $\begin{array}{l}\text { C-H Out of plane in positions } 2,5 \text {, and } 6 \text { of G- } \\
\text { units }\end{array}$ & - & - \\
\hline
\end{tabular}




\section{${ }^{1} \mathrm{H}-\mathrm{NMR}$ Analysis}

The integrated ${ }^{1} \mathrm{H}-\mathrm{NMR}$ spectra for the soluble and dioxane lignins are shown in Fig. 2. Table 2 lists the positions of signals assigned from previous reports (Jahan and Mun 2007; Kang and Zhou 2012; Yang et al. 2013b). In combination with the above FTIR analysis and the ${ }^{1} \mathrm{H}$-NMR signals of the $p$-hydroxyphenyl aromatic protons $(\delta 7.48 \mathrm{ppm}$ and $7.49 \mathrm{ppm}$ ), the soluble lignin from PHL could be justified as HSG lignin. According to Table 2, the phenolic hydroxyl (Ar-OH) content of the soluble lignin was lower than that of dioxane lignin, which indicated that the rupture of aryl-ether bond occurred during prehydrolysis (Jahan et al. 2012; Yang et al. 2013b).

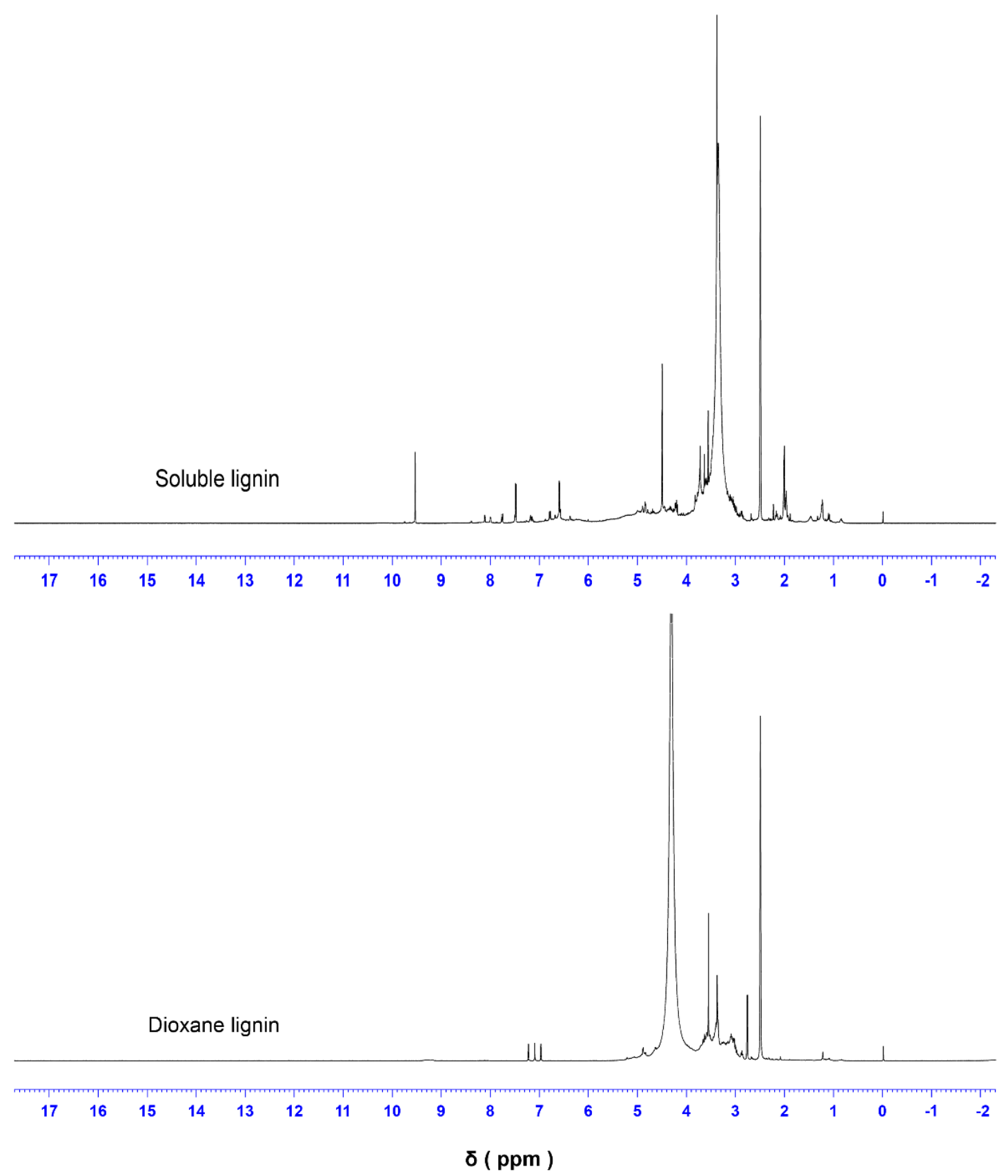

Fig. 2. ${ }^{1} \mathrm{H}-\mathrm{NMR}$ spectra of the soluble and dioxane lignins 
It is noteworthy that both soluble and dioxane lignins possessed absorbance peaks at the range of $\delta 3.00 \mathrm{ppm}$ to $4.15 \mathrm{ppm}$ (methoxyl groups). Further, the methoxyl content of soluble lignin was lower than that of dioxane lignin, indicating the demethylation of the aromatic methoxyl groups in the lignin structure occurred during pre-hydrolysis, this was consistent with the results of Ibrahim et al. (2010). In addition to this observation, the peak strength at $2.49 \mathrm{ppm}$ was also strong, which denotes the absorbance peak for solvent DMSO-d6 (Tong 2017). The absorbance peaks at $\delta 1.23 \mathrm{ppm}$ and $1.24 \mathrm{ppm}$ correspond to the hydrogen atom in aliphatic groups, which may be caused by carbohydrates. Additionally, the cinnamyl alcohol structure was detected in both soluble $(\delta 4.34 \mathrm{ppm}$ to $4.84 \mathrm{ppm})$ and dioxane ( $\delta 4.31 \mathrm{ppm}$ to $4.91 \mathrm{ppm})$ lignins.

Table 2. Assignments of Signals in the ${ }^{1} \mathrm{H}-\mathrm{NMR}$ Spectra of Soluble and Dioxane Lignins

\begin{tabular}{|c|c|c|c|}
\hline $\begin{array}{c}\text { Range } \delta \\
(\mathrm{ppm})\end{array}$ & Assignments & Soluble Lignin & $\begin{array}{c}\text { Dioxane } \\
\text { Lignin }\end{array}$ \\
\hline 0.38 to 1.58 & High-shadowing aliphatic proton & $1.23,1.24$ & 1.22 \\
\hline 1.58 to 2.19 & $\mathrm{H}$ of aliphatic acetates & $\begin{array}{c}1.96,1.97,2.00, \\
2.01\end{array}$ & - \\
\hline 2.19 to 2.50 & $\mathrm{H}$ of aromatic acetates & $2.23,2.49$ & 2.49 \\
\hline 2.50 to 3.00 & $\mathrm{H}_{\beta}$ of $\beta-1, \beta-5$, and $\beta-\beta$ structures & 2.98 & 2.76 to 3.00 \\
\hline 3.00 to 4.15 & $\mathrm{H}$ of methoxyl groups & 3.01 to 3.83 & 3.00 to 4.00 \\
\hline 4.15 to 4.30 & $\mathrm{H}_{\mathrm{y}}$ of $\beta-1, \beta-5, \beta-\mathrm{O}-4$, and $\beta-\beta$ structures & $\begin{array}{c}4.19,4.20,4.21, \\
4.23\end{array}$ & - \\
\hline 4.30 to 5.18 & $\begin{array}{c}\mathrm{H} \alpha \text { of } \beta-\beta \text { structure, } \mathrm{H}_{\beta} \text { of } \beta \text {-O-4 structure, } \\
\text { and } \mathrm{H}_{\gamma} \text { of cinnamyl alcohol structure }\end{array}$ & $\begin{array}{c}4.34 \text { to } 4.84 \\
4.31 \text { to } 4.91\end{array}$ \\
\hline 6.28 to 6.80 & Aromatic proton in syringyl units & 6.59 to 6.60 & - \\
\hline 7.30 to 7.80 & Aromatic proton in $p$-hydroxyphenyl units & $7.48,7.49$ & - \\
\hline 8.00 to 11.5 & Protons in carboxyl and aldehyde groups & 9.54 & - \\
\hline
\end{tabular}

\section{D-HSQC Analysis}

To further understand the structural characteristics of the soluble lignin obtained from PHL, qualitative 2D-HSQC spectra of the soluble and dioxane lignins were recorded and are shown in Fig. 3, and the detailed peak assignments are presented in Table 3 (Del Rio et al. 2009; Xiao et al. 2012; Chen et al. 2019). The structure of the soluble lignin obtained from PHL can be analyzed more intuitively by combining the structure diagrams of several dimers, such as $\beta$-ether $(\beta-\mathrm{O}-4, \mathrm{~A})$, and $\mathrm{H}, \mathrm{S}, \mathrm{G}$-monomers of lignin as shown in Fig. 3 (Xiao et al. 2012).

In the side-chain region, the signal of $\mathrm{C}-\mathrm{H}$ in methoxy group in the spectrum showed a strong correlation signal at $\delta \mathrm{C} / \delta \mathrm{H} 56.0 / 3.7 \mathrm{ppm}$. The signals at $\delta \mathrm{C} / \delta \mathrm{H} 63.5 / 4.2$ ppm were assigned to the $\mathrm{C} \gamma-\mathrm{H} \gamma$ in $\gamma$-acetylated $\beta-\mathrm{O}-4^{\prime}$ substructures $\left(\mathrm{A}^{\prime} / \mathrm{A}^{\prime \prime}\right)$, indicating that the $\beta-\mathrm{O}-4^{\prime}$ structure of the soluble lignin obtained from PHL underwent an acetylation reaction at the $\gamma$ position. The signals of the methoxy groups and $\beta$-O-4' substructures (substructure A) were the most prominent ones in both soluble and dioxane lignins. The signals corresponding to spirodienone $\left(\beta-1^{\prime}\right)$ substructures (D) could also be confirmed in the spectra of the soluble lignin, its $\mathrm{C}_{\beta}-\mathrm{H}_{\beta}$ correlation being at $\delta \mathrm{C} / \delta \mathrm{H} 61.1 / 3.2 \mathrm{ppm}$, and the schematic is shown in Fig. 3D. In the aromatic region, the signals of $\mathrm{C}_{2}-\mathrm{H}_{2}$ in guaiacyl units $(\mathrm{G})$ were found at $\delta \mathrm{C} / \delta \mathrm{H} 110 / 6.7 \mathrm{ppm}$ in both soluble and dioxane lignin, suggesting that both soluble and dioxane lignins possessed a G-type structural unit, which is in agreement with the results of FTIR spectroscopy. Additionally, the signals at $\delta \mathrm{C} / \delta \mathrm{H}$ 
123.0/7.5 ppm were assigned to $\mathrm{C}_{6}-\mathrm{H}_{6}$ in ferulic acid ester, indicating that there was a ferulic acid ester structure in the soluble lignin from PHL.

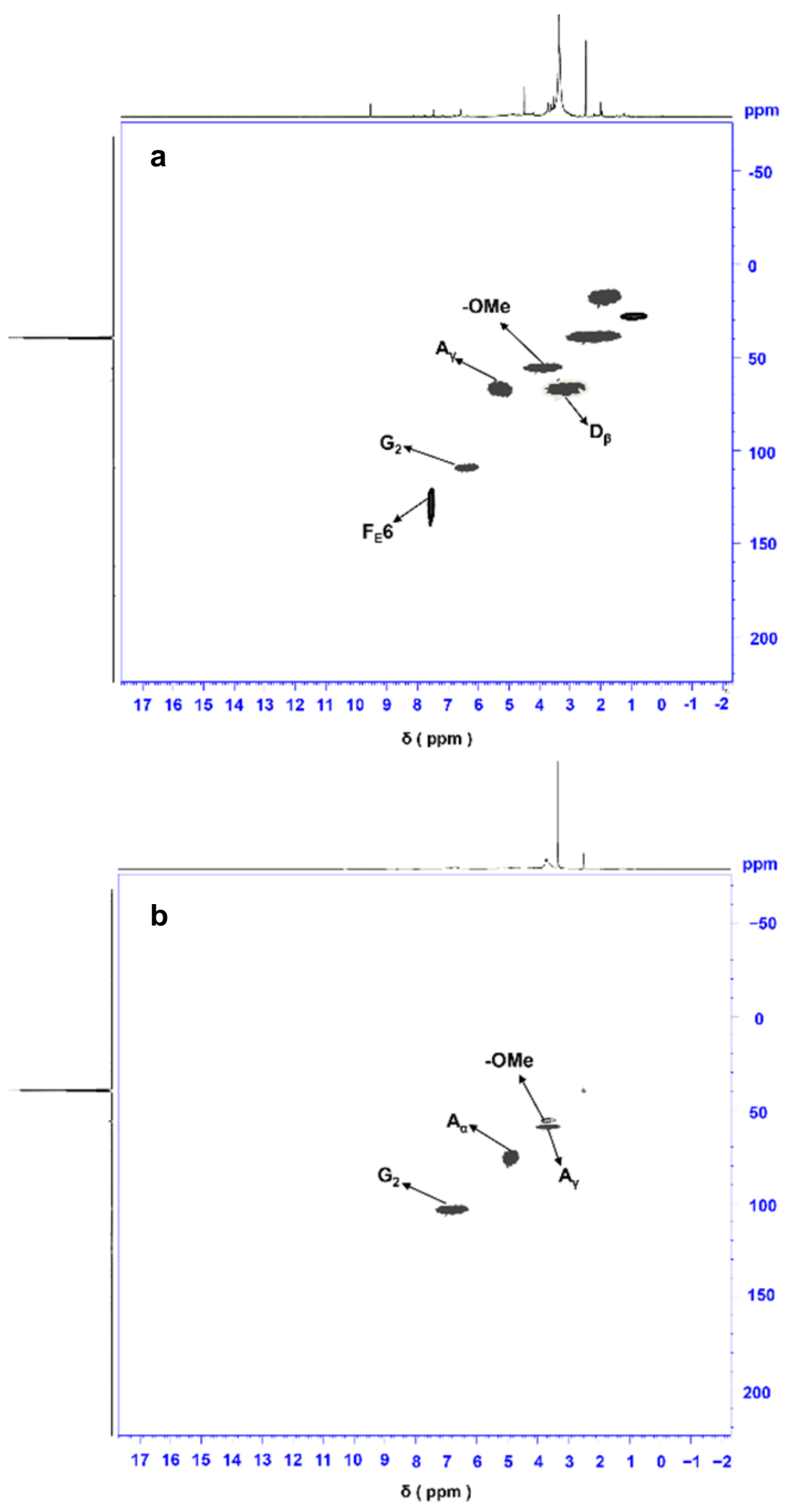


<smiles>[Z]c1cc(OC)c(OC(CO)C(O)c2cc(OC)c(OCCC)c(OC)c2)c(OC)c1</smiles><smiles>[Z]c1cc(OC)c(OC(COC(C)=O)C(O)c2cc(OC)c(OC)c(OC)c2)c(OC)c1</smiles><smiles>[Z]c1cc(OC)c(OC(COP(=O)(O)c2ccccc2)C(O)c2cc(OC)c(OCCC)c(OC)c2)c(OC)c1</smiles>

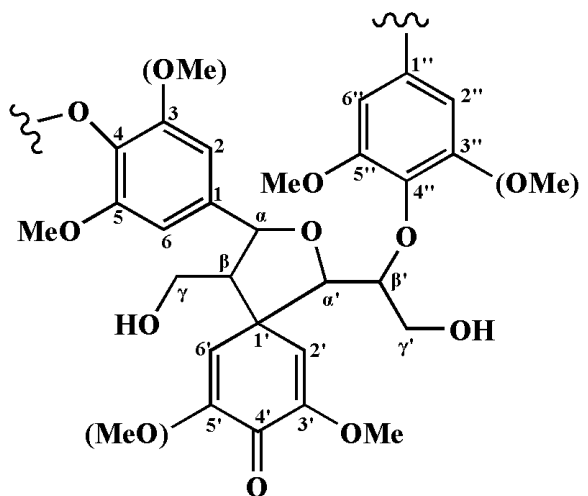

D<smiles>CCOc1c(OC)cc(C(O)O)cc1OC</smiles>

G(S)

Fig. 3. 2D-HSQC spectra of the soluble (a); and dioxane (b) lignins. The lignin substructures are also shown: (A) $\beta$-O-4' linkages; (A', A") $\beta$-O-4' linkages with acetylated $\gamma$-carbon; (D) $\mathrm{C}-\mathrm{H}$ coupling structure of spiro structure; and $(G(S))$ guaiacyl unit or syringyl unit

Table 3. Assignments of Signals in the 2D-HSQC Spectra of Soluble and Dioxane Lignin

\begin{tabular}{|c|c|c|}
\hline Label & $\delta_{\mathrm{c} / \delta_{\mathrm{H}}(\mathrm{ppm})}$ & Assignments \\
\hline$-\mathrm{OMe}$ & $56.0 / 3.76$ & $\mathrm{C}-\mathrm{H}$ in methoxyls \\
\hline $\mathrm{A}_{\mathrm{Y}}^{\prime}\left(\mathrm{A}_{\mathrm{Y}}^{\prime \prime}\right)$ & $63.5 / 4.2$ & $\mathrm{C}_{\mathrm{Y}}-\mathrm{H}_{\mathrm{Y}}$ in $\mathrm{Y}_{\text {-acetylated } \beta-\mathrm{O}-4^{\prime} \text { substructures }\left(\mathrm{A}^{\prime} / \mathrm{A}^{\prime \prime}\right)}$ \\
\hline $\mathrm{A}_{\alpha(\mathrm{S})}$ & $4.85 / 72.0$ & $\mathrm{C}_{\alpha}-\mathrm{H}_{\alpha}$ in $\beta$-O-4' substructures linked to a S unit (A) \\
\hline $\mathrm{D}_{\beta}$ & $61.1 / 3.2$ & $\mathrm{C}_{\beta}-\mathrm{H}_{\beta}$ in $\beta-1^{\prime}$ (spirodienone) substructures (D) \\
\hline $\mathrm{G}_{2}$ & $110 / 6.7$ & $\mathrm{C}_{2}-\mathrm{H}_{2}$ in guaiacyl (G) \\
\hline $\mathrm{F}_{\mathrm{E} 6}$ & $123.0 / 7.5$ & $\mathrm{C}_{6}-\mathrm{H}_{6}$ in Ferulic acid ester \\
\hline
\end{tabular}

\section{Thermogravimetric Analysis}

The thermal stability is a vital parameter for thermosetting or thermoplastic materials. Figure 4 shows the TG and derivative TG (DTG) curves of the soluble lignin obtained from PHL and dioxane lignin. The obtained soluble lignin sample had a maximum mass loss peak at $200{ }^{\circ} \mathrm{C}$, which indicated the temperature at which hemicellulose begins to decompose was at approximately $200{ }^{\circ} \mathrm{C}$. The maximum thermal decomposition of 
lignin was observed at $350{ }^{\circ} \mathrm{C}$ to $450{ }^{\circ} \mathrm{C}$ (Liu 2009), consequently, hemicellulose has completed most of the decomposition when lignin begins to decompose. It can be seen that the maximum mass loss rate at $200{ }^{\circ} \mathrm{C}$ was caused by the decomposition of hemicellulose, which was due to the hemicellulose contained in the soluble lignin sample obtained by the activated carbon adsorption method.
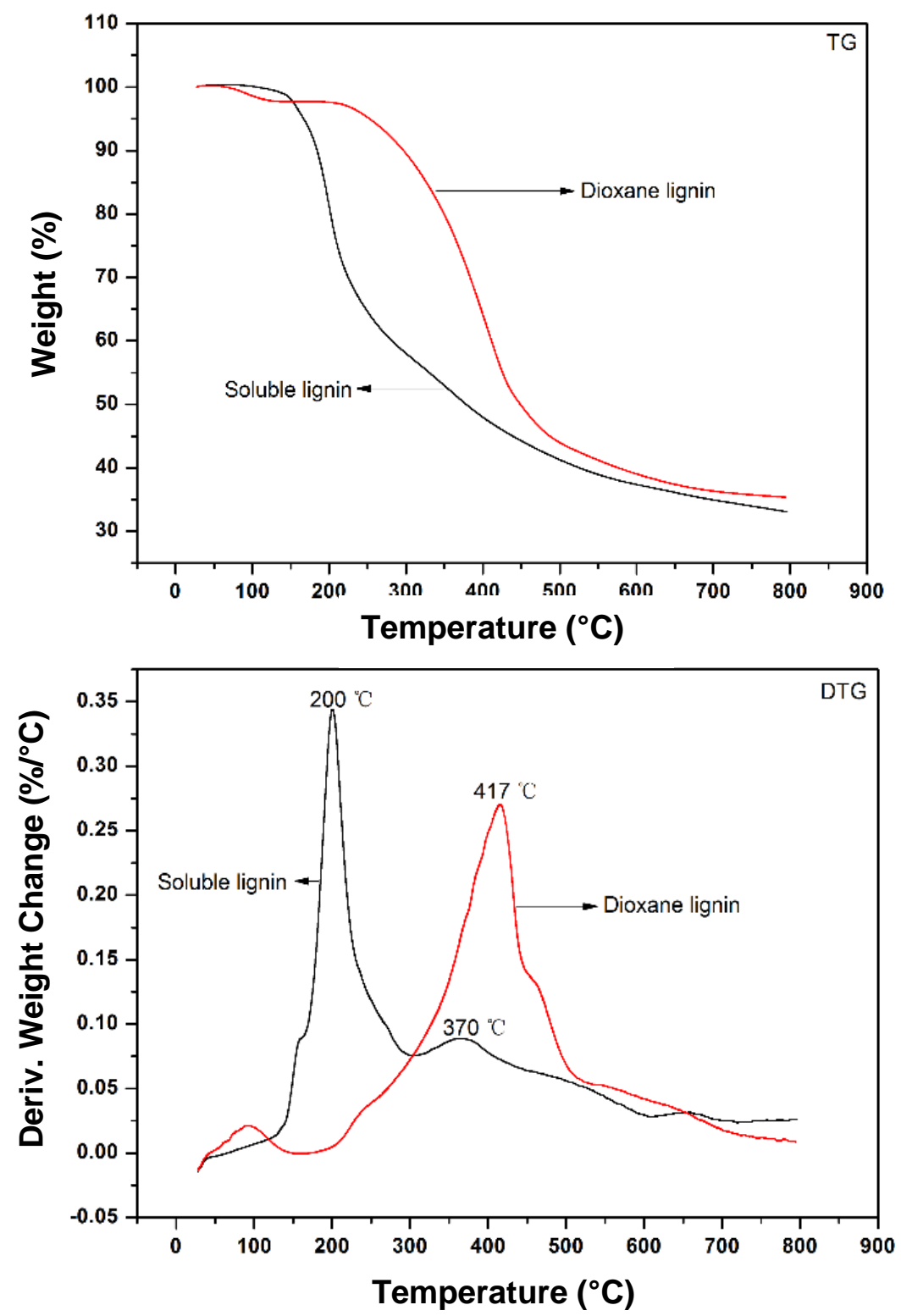

Fig. 4. TG/DTG curves of the soluble and dioxane lignins

The maximum thermal decomposition rate temperatures of soluble and dioxane lignins were at $370{ }^{\circ} \mathrm{C}$ and $417^{\circ} \mathrm{C}$, respectively. Previous literature also reported that the aromatic ring of lignin molecules began to disintegrate at temperatures above $400{ }^{\circ} \mathrm{C}$ (Sun et al. 2001). Above $500{ }^{\circ} \mathrm{C}$, the mass loss and mass loss rate of soluble lignin and dioxane lignin basically converge. The residual char yields determined at $800{ }^{\circ} \mathrm{C}$ of soluble and dioxane lignins were $33.36 \%$ and $35.30 \%$, respectively. Approximately $2 \%$ of yield gap between the two samples can be ascribed to the existence of hemicellulose component in 
the obtained soluble lignin from PHL. Notably, the residual char yields of the two samples turned out to be almost the same, which exactly indicated that the main component of the sample obtained from PHL by activated carbon adsorption was lignin. Therefore, the soluble lignin obtained from PHL possessed thermal stability comparable to dioxane lignin, and the mixture of lignin and hemicelluloses can be used to produce carbon fiber by a combination process of electrospinning, carbonization and activation.

\section{CONCLUSIONS}

1. The present study compared the structural characteristics of soluble lignin in the PHL and dioxane-extracted lignin from bamboo-willow dissolving pulp. Results showed that the cleavage of $\beta$-O- 4 aryl-ether linkages and demethylation occurred in the lignin structure during the pre-hydrolysis step.

2. The soluble lignin isolated from PHL could be identified as $p$-hydroxyphenyl-syringylguaiacyl (HSG) lignin, and the main linker bonds between structural units of soluble lignin were $\beta-\beta, \beta-5, \beta-1$, and $\beta-\mathrm{O}-4$.

3. The soluble lignin obtained from PHL possessed thermal stability comparable to dioxane lignin from bamboo-willow material. This study will hopefully provide some guidance for the resource utilization and selective removal of soluble lignin in the PHL.

\section{ACKNOWLEDGMENTS}

The authors gratefully acknowledge the financial support from the National Science Foundation of Shandong Province (No. ZR2017LC016), the Open Fund of National Key Laboratory of Pulp and Paper Engineering, and the South China University of Technology (201817). The authors also appreciate the financial support from a project of Shandong Province Higher Educational Science and Technology Program (No. J17KA142) and the National Key R\&D Program of China (2017YFB0307900).

\section{REFERENCES CITED}

Bardet, M., Robert, D., and Lundquist, K. (1985). "On the reactions and degradation of the lignin during steam hydrolysis of aspen wood," Svensk Papperstidning 88(6), r61r67.

Buta, J. G., Zadrazil, F., and Galletti, G. C. (1989). "FT-IR determination of lignin degradation in wheat straw by white rot fungus Stropharia rugosoannulata with different oxygen concentrations," Journal of Agricultural and Food Chemistry 37(5), 1382-1384. DOI: 10.1021/jf00089a038

Capanema, E. A., Balakshin, M. Y., and Kadla, J. F. (2005). “Quantitative characterization of a hardwood milled wood lignin by nuclear magnetic resonance spectroscopy," Journal of Agricultural and Food Chemistry 53(25), 9639-9649. DOI: 10.1021/jf0515330

Chen, X., Cao, X., Sun, S., Yuan, T., Wang, S., Shi, Q., and Sun, R. (2019).

"Hydrothermal acid hydrolysis for highly efficient separation of lignin and xylose 
from pre-hydrolysis liquor of kraft pulping process," Separation and Purification Technology 209, 741-747. DOI: 10.1016/j.seppur.2018.09.032

Chua, M. G. S., and Wayman, M. (1979). "Characterization of autohydrolysis aspen ( $P$. tremuloides) lignins. Part 3: Infrared and ultraviolet studies of extracted autohydrolysis lignin," Canadian Journal of Chemistry 57(19), 2603-2611. DOI: $10.1139 / \mathrm{v} 79-421$

Constant, S., Basset, C., Dumas, C., Di Renzo, F., Robitzer, M., Barakat, A., and Quignard, F. (2015). "Reactive organosolv lignin extraction from wheat straw: Influence of Lewis acid catalysts on structural and chemical properties of lignins," Industrial Crops and Products 65, 180-189. DOI: 10.1016/j.indcrop.2014.12.009

Del Rio, J. C., Rencoret, J., Marques, G., Li, J., Gellerstedt, G., Jimenez-Barbero, J., Martinez, A. T., and Gutierrez, A. (2009). "Structural characterization of the lignin from jute (Corchorus capsularis) fibers," Journal of Agricultural and Food Chemistry 57(21), 10271-10281. DOI: 10.1021/jf900815x

Evtuguin, D. V., Neto, C. P., Silva, A. M. S., Domingues, P. M., Amado, F. M. L., Robert, D., and Faix, O. (2001). "Comprehensive study on the chemical structure of dioxane lignin from plantation Eucalyptus globulus wood," Journal of Agricultural and Food Chemistry 49(9), 4252-4261. DOI: 10.1021/jf010315d

Ibrahim, M. M., Agblevor, F. A., and El-Zawawy, W. K. (2010). "Isolation and characterization of cellulose and lignin from steam-exploded lignocellulosic biomass," BioResources 5(1), 397-418. DOI: 10.15376/biores.5.1.397-418

Jahan, M. S., Liu, Z., Wang, H., Saeed, A., and Ni, Y. (2012). "Isolation and characterization of lignin from prehydrolysis liquor of kraft-based dissolving pulp production," Cellulose Chemistry and Technology 46(3-4), 261-667.

Jahan, M. S., and Mun, S. P. (2007). "Characteristics of dioxane lignins isolated at different ages of nalita wood (Trema orientalis)," Journal of Wood Chemistry and Technology 27(2), 83-98. DOI: 10.1080/02773810701486865

Kang, S., Xiao, L., Meng, L., Zhang, X., and Sun, R. (2012). "Isolation and structural characterization of lignin from cotton stalk treated in an ammonia hydrothermal system," International Journal of Molecular Sciences 13(11), 15209-15226. DOI: 10.3390/ijms 131115209

Kang, S.-M., and Zhou, J.-C. (2012). "The application of NMR in lignin structure research," China Pulp and Paper 31(10), 58-63.

Kumar, H., and Christopher, L. P. (2017). "Recent trends and developments in dissolving pulp production and application," Cellulose 24(6), 2347-2365. DOI: 10.1007/s10570017-1285-y

Lee, H. -J., Lim, W. -S., and Lee, J. -W. (2013). "Improvement of ethanol fermentation from lignocellulosic hydrolysates by the removal of inhibitors." Journal of Industrial and Engineering Chemistry 19(6), 2010-2015. DOI: 10.1016/j.jiec.2013.03.014

Leschinsky, M., Zuckerstätter, G., Weber, H. K., Patt, R., and Sixta, H. (2008). "Effect of autohydrolysis of Eucalyptus globulus wood on lignin structure. Part 1: Comparison of different lignin fractions formed during water prehydrolysis," Holzforschung 62(6), 645-652. DOI: 10.1515/hf.2008.117

Liu, Q. (2009). Biomass Pyrolysis Mechanism Based on the Multi-components, Ph.D. Dissertation, Zhejiang University, Zhejiang, China.

Lora, J. H., and Wayman, M. (1980). "Autohydrolysis of aspen milled wood lignin," Canadian Journal of Chemistry 58(7), 669-676. DOI: 10.1139/v80-102 
Mašura, M. (1987). "Prehydrolysis of beechwood," Wood Science and Technology 21(1), 89-100. DOI: 10.1007/BF00349720

Schorr, D., Diouf, P. N., and Stevanovic, T. (2014). "Evaluation of industrial lignins for biocomposites production," Industrial Crops and Products 52(12), 65-73. DOI: 10.1016/j.indcrop.2013.10.014

Shen, J., Fatehi, P., Soleimani, P., and Ni, Y. (2011). "Recovery of lignocelluloses from pre-hydrolysis liquor in the lime kiln of kraft-based dissolving pulp production process by adsorption to lime mud," Bioresource Technology 102(21), 10035-10039. DOI: 10.1016/j.biortech.2011.08.058

Shen, J., Kaur, I., Baktash, M. M., He, Z., and Ni, Y. (2013). “A combined process of activated carbon adsorption, ion exchange resin treatment and membrane concentration for recovery of dissolved organics in pre-hydrolysis liquor of the kraftbased dissolving pulp production process," Bioresource Technology 127, 59-65. DOI: 10.1016/j.biortech.2012.10.031

Sluiter, A., Hames, B., Ruiz, R., Scarlata, C., Sluiter, J., and Templeton, D. (2006). Determination of Sugars, Byproducts, and Degradation Products in Liquid Fraction Process Samples, U. S. National Renewable Energy Laboratory, Golden, CO, USA.

Sun, R., Lu, Q., and Sun, X. F. (2001). "Physico-chemical and thermal characterization of lignins from Caligonum monogoliacum and Tamarix spp.," Polymer Degradation and Stability 72(2), 229-238. DOI: 10.1016/S0141-3910(01)00023-4

Tong, R. (2017). Study on Lignin Removal Mechanism in Pre-hydrolysis Liquor of the Dissolving Pulp from Bamboo, Master's Thesis, Qilu University of Technology, Shandong, China.

Tong, R., Wu, C., Zhao, C., and Yu, D. (2017). "Separation and structural characteristics of lignin in the prehydrolysis liquor of whangee dissolving pulp," BioResources 12(4), 8217-8229. DOI: 10.15376/biores.12.4.8217-8229

Wang, Q., Jahan, M. S., Liu, S., Miao, Q., and Ni, Y. (2014a). "Lignin removal enhancement from prehydrolysis liquor of kraft-based dissolving pulp production by laccase-induced polymerization," Bioresource Technology 164, 380-385. DOI: 10.1016/j.biortech.2014.05.005

Wang, Z., Jiang, J., Wang, X., Fu, Y., Li, Z., Zhang, F., and Qin, M. (2014b). "Selective removal of phenolic lignin derivatives enables sugars recovery from wood prehydrolysis liquor with remarkable yield," Bioresource Technology 174, 198-203. DOI: 10.1016/j.biortech.2014.10.025

Xiao, L. -P., Shi, Z. -J., Xu, F., and Sun, R. -C. (2012). "Characterization of MWLs from Tamarix ramosissima isolated before and after hydrothermal treatment by spectroscopical and wet chemical methods," Holzforschung 66(3), 285-302. DOI: 10.1515/hf.2011.154

Yang, G., Jahan, M. S., Ahsan, L., Zheng, L., and Ni, Y. (2013a). "Recovery of acetic acid from pre-hydrolysis liquor of hardwood kraft-based dissolving pulp production process by reactive extraction with triisooctylamine," Bioresource Technology 138, 253-258. DOI: 10.1016/j.biortech.2013.03.164

Yang, G., Jahan, M. S., and Ni, Y. (2013b). "Structural characterization of pre-hydrolysis liquor lignin and its comparison with other technical lignins," Current Organic Chemistry 17(15), 1589-1595. DOI: 10.2174/13852728113179990068

Zhang, J. -C., Wu, C. -J., and Yu, D. -M. (2019). "Effect of phosphoric acid in the prehydrolysis process of dissolving pulp production from bamboo-willow," BioResources 14(2), 3117-3131. DOI: 10.15376/biores.14.2.3117-3131 
Zhao, J., Xiuwen, W., Hu, J., Liu, Q., Shen, D., and Xiao, R. (2014). “Thermal degradation of softwood lignin and hardwood lignin by TG-FTIR and Py-GC/MS," Polymer Degradation and Stability 108, 133-138. DOI:

10.1016/j.polymdegradstab.2014.06.006

Article submitted: September 3, 2019; Peer review completed: November 17, 2019; Revised version received and accepted: December 9, 2019; Published: December 11, 2019.

DOI: $10.15376 /$ biores.15.1.825-839 